\title{
Engaging families in Partnership through Technology
}

\author{
Wei LIU*, Shan LU ${ }^{\mathrm{b},{ }^{*}}$ \\ Education Faculty, Monash University, 100 Clyde Rd, Berwick VIC 3806 Australia \\ wliu88@student.monash.edu
}

Keywords: Leadership and management, Meaningful partnership, Communication, Technology.

\begin{abstract}
Partnership between families and early childhood educators has assumed importance in Australian government policy and document. A collaborative partnership plays a vital role in supporting children's learning and development. However, many traditional ways in building partnership with families are not effective and are not suitable to the changing of nowadays communication styles. This research project takes on the leaders view in early childhood education; the author draws on knowledge about how to build a meaningful partnership between early childhood educators and families, on which research methods such as survey, interview and questionnaire are used to get data about the opinions of using technology to build partnership. Professional leadership are emphasized in policy making on partnership meanwhile leaders need to consider the challenges that they faced when using technology to support the communication.
\end{abstract}

\section{Introduction and Rationale}

Engaging families in various levels and types of collaborative partnership has always been a core component of early childhood service delivery, as young children's learning and developmental outcomes are greatly enhanced when strong partnerships are successfully established between early childhood educators and families. Research consistently demonstrates that meaningful partnership with families is crucial in supporting and extending children's learning and equitable outcomes [1, 2], as well as ensuring a smooth transition and continuity in children's lives [3]. Working effectively with young children and their families is the foundation of everyday practice for early childhood professionals around the world. In Australia, the focus on fostering positive partnerships with families is outlined in Australian policy documents to guide and mandate early childhood practice and qualifications. It also places a stronger emphasis on educators' understanding of meaningful family engagement in service delivery and provision [4].

Traditional strategies often used by educational settings to involve parents in children's learning includes sending home school bulletins, printed newsletters, copies of photographs, talking with parents on the phone, organising parent meetings, home visits and using suggestion boxes for parents to write their recommendations for improvement [5,6]. However, research has shown that the development of meaningful parental involvement in any setting can be challenging, and these previously mentioned strategies are often ineffective and do not truly support families involvement [7]. For instance, schools normally use printed newsletters to share children's experiences at the setting with families. However, this one-way transmission of information may not maintain effective ongoing communication with families. Consequently, it is important for early childhood leaders and educators to find innovative and meaningful ways of engaging all families in articulating and communicating their perspectives, beliefs and concerns in order to better engage families in partnerships.

In recent years, as information technology develops rapidly, the implementation of technology to support partnership between educators and families has been worthy of consideration, as it may have a positive impact on parental communication [8, 9, 10] and increase active parental involvement [1]. Short message services, for instance, could provide information directly to parents and short messages are more timely and easier to manage [11]. More importantly, this will increase opportunities to contact, connect and communicate with families and enhance collaboration. An E-Homebook System (EHS) was introduced in Taiwan [12], which provided a teacher-parent-student 
interaction interface through web-based communication, in order to better involve families and shared decision-making about their children's learning and education.

However, because proactive involvement does not require parents to be physically present at their children's early childhood settings, the question of how technology can be used to maintain parental involvement in their children's academic lives has arisen in a number of research projects. In particular, its impact on different stakeholders has been widely discussed in various studies as the whole society is wondering where technology can support positive collaboration with families. Moreover, only a limited portion of the literature suggests how to engage families in partnership through technology in the early childhood settings $[9,13]$. These researchers do not recommend specific, empirically grounded strategies for early childhood educators to work collaboratively with families through technology $[2,7]$. As leaders, we are interested in exploring innovative strategies to increase parent-educator collaboration, in order to improve our service quality for children and families eventually.

As indicated above, parental involvement has been associated with increased educational benefits and social competence and the benefits of using technology in education are well supported. Therefore, the focus question for this project is: How technologies can be used to facilitate better parent-educator communication and parental involvement?

The research project takes on the roles of early childhood leaders' views. It commences with a description of the investigative methods employed to explore the focus question of our chosen topic and includes a survey, an interview and questionnaires to analyse both educators' and families' perspectives and attitudes to implement an electronic communication strategy. Through reviewing a range of literature and published media reports, the positive impacts and challenges in implementation are explored. The project focuses on investigating how the technology can increase communication and support parental involvement. Drawing on the relevant literature, the last part of the project will discuss the significance of this project to early childhood policy and practice in relation to leadership and management.

\section{Methods of Investigation}

An action research approach will be used in this research project, to bridge the gap between research and practice, as well as enhancing professional learning and fosters reflection [14]. As leaders, we understand that collaborative processes promote communication and understanding, and help to ensure that jargon-free research findings are made available and presented in simple and intelligent ways [15]. Therefore, multiple data collection tools will be used to gather information. Before implementation of the action research, the educators and parents' perceptions of using technology communication will be obtained through a survey. An interview provides information of the benefits and challenges for using technology and promotes parental involvement. During implementation of the action research, two questionnaires with the individual educators and family members will be used to evaluate the results of the action research. The participants of the study will include all family members and professionals (e.g. the managers, the directors, educators and centre staffs) in the Centre.

\section{Survey}

A quantitative survey will be one of the important tools, which helps to support the study by allowing leaders to gather information about the views and attitudes hold by both educators and family members about implementing technology communication instead of using traditional strategies. As leaders, we can administer the survey to individual parents and educators in order to gain an overall impression. We believe that the educators and families' attitude and views will influence future implementation. The survey results can be very useful in deciding what sort of additional information to pursue in order to establish inclusive and meaningful family engagement. In addition, the survey can produce some valuable information about the children's family practices, beliefs and expectations, as it is fundamental to family members feeling a sense of security and belonging [3]. 


\section{Interview}

In-depth interviews will be another valuable source of data designed to assist the leaders to identify the challenges for using technology to promote parent involvement. Interview questions focus on educators' and families' perspectives on the benefits/limitations of using technologies for parental involvement, and understanding how the centre will implement and utilise the technologies. Interviews with individual parents could offer real opportunities for families to have a voice and be heard, as well as 'play a legitimate role with significant functions' [15, p. 227]. As leaders, we enact leadership which will affect the development of meaningful family engagement. In addition, the interview format we will use is a semi-structured scheduled interview [16], with a list of possible questions, but was not restricted to specific phrasing or a particular order of questions. Interviewees' responses about the challenges and problems associated with using technology communication would provide us as leaders with an insight into our current practice as they indicate what we should be aware of and where we need to improve when building partnerships through using technology.

\section{Questionnaires}

During the research phase, two questionnaires are prepared for the educators and family members separately, and aim to evaluate and reflect 'the effects of the informed action and to make sense of the processes and issues that emerge' [15, p. 214]. We believe that the evaluation is a crucial step in justifying the methods we used. The questionnaire for educators consists of 10 questions and the results suggest whether the educators need further training on how to use technology and provide possible solutions. Questions also probed for follow-up communication and clarification, which would allow us as leaders to respond to the need for change. The parent questionnaire consists of 8 questions and aims to record family requirements and expectations in implementation. Questions such as: Do I experience respectful attitudes and interactions through using technology? How often will I initiate communication with educators through using technology? Allowing all the parents to actively participate in the initial conversation ensures that their critical questions are fully answered.

Overall, the results of survey, the interviews and the questionnaires suggest what we must consider and overcome to ensure an effective and supportive strategy in building collaborative partnerships and connections between home and the early childhood settings. As leaders we will evaluate and make changes in using these methods as needed

\section{Literature Review}

The literature review includes three sections. It will first introduce the idea of existing partnerships and move towards meaningful partnerships in the practice of teaching by reviewing the theoretical foundations and related literature. This is then followed by examining the role technology plays in parental involvement by discussing the benefits of increasing communication opportunities and encouraging parental engagement. The third part of the literature review will discuss the factors and issues underpinning the use of technology with families from both educators' and families' perspectives.

\section{From partnerships to meaningful partnerships}

As early as 1970s, partnerships with families in early childhood have been variously described, researched and analysed. In the field of early years, researchers frequently cite Bronfenbrenner's model (1979) of the child as evidence that the significance of sociocultural factors must be taken into account by all early childhood professionals [10]. Similarly, cultural-historical theory also puts emphasis on the role of social and cultural contexts for children's learning and development within early childhood education [3]. In other words, children's future success greatly depends on their personal, family and cultural histories.

Today, family engagement in early childhood service delivery and provision is an essential feature of quality. A growing body of research is demonstrating the importance of involving families in early childhood programs, with previous interest focused on themes of [15]:

- Partnership: a philosophy of shared child-rearing 
- Continuity: the promotion of consistency between service and home, and

- Education: the professional responsibility to support and educate families to enhance children's wellbeing, as well as family enjoyment and competence in child-rearing (p. 222).

Nevertheless, transforming family participation and involvement in early childhood services from a typically token level to meaningful partnership is not an easy task to achieve and there are certain challenges associated with it. On one hand, building collaborative relationships with families is a developmental process that takes time, experience and considerable effort. Sufficient time is required to establish structural elements such as connecting with each other, exchanging children's information, sharing each other's experiences etc. [17]. However, lack of time, for both families and educators is a major challenge for building respectful relationships, which are the foundation of shared understanding, collaborative partnership and meaningful engagement [18].

On the other hand, facing various cultural backgrounds can be another challenge in building positive partnerships. According to the 2013 census [19], it is estimated that at least one quarter of the Australian were born overseas and 400 languages are spoken in Australia, including the many different languages that are spoken by Aboriginal and Torres Strait Islander Australians. This extensive culture and linguistic diversity within the Australian population is well reflected in early childhood settings and schools [18]. Consequently, while educators understand that communication is the key to positive interactions, language barriers can be too difficult to overcome. Furthermore, it is difficult enough to communicate effectively with families about their children's progress; however, to involve them in the educational process is another challenge for educators.

For partnerships to be meaningful, we believe that it is worthwhile to spend time discovering and examining innovative and effective ways and it is our belief that the meaningful partnership could be achieved through using technology.

\section{Engaging families in partnership through technology}

Researchers have frequently suggested that digital tools may be used as effective platform to connect with families and establish closer relationships. Different literature sources focus on the impact of the use of technology and social media. Many positive influences could be found in the following two aspects:

Firstly, modern information technology makes communication prompt and convenient and families have more conversation opportunities with educators. Many studies have identified the importance of communication in successfully negotiating relationships with families [3, 15] and actively engaging them with early childhood services. Educators and families exchange information and share understandings through communication, which allow them to work cooperatively to support the child's learning outcomes. Studies also suggest that two-way communication between educators and families simultaneously keeps families informed about their children's learning situation and school activities [11, 20]. Today's educators are increasingly turning to a variety of digital technologies to make communication with families easier and more current. Through Twitter feeds, Facebook pages, and text messages sent in multiple languages, educators are offering families with instant updates, news and information about their children. Christine [11] advocates that communication through digital tools saves time, ease language barriers through translation services, and provide opportunities to reach more parents than ever before, no matter their socioeconomic status. Some educational settings, for instance, address technology as an important reform strategy to contact families -- both individually and in groups [21] which allow the families to feel a sense of belonging [22].Adopting web-based communication to exchange information between educators and parents could be an effective communication medium. As highlighted by Kosaretskii and Chernyshova [23], educator-parent communication supported by web-based information systems positively influences parental involvement. When data is entered into the system by high activity by educators on daily and regular basis, data usage and system use from also parents increases [24]. Integrating technology into their communication strategy helps educators to reach many parents in no time and to solve the home-center communication problems [25]. Blogs, for instance, could increase active two-way opportunities between educators and families [26]. The blogs are most commonly used to share newsletters and information bulletins with parents, as well as to convey important 
messages regarding specific activities or developments. The blog also provides links to social networking sites such as YouTube and provides opportunities especially for parents who speak English as their second language to know about their children's experience virtually.

Secondly, the use of technology is broadly viewed as a useful tool to encourage families' engagement. According to Mullen and Wediwick [27], the new generations have grown up with digital access and expect to use technology in their day-to-day lives. Educators and families are encouraged to use phones, computers, and social networking sites frequently to share new information about children's learning and development [26]. Australia has recognised this phenomenon as a great avenue for communication between educational settings and home and has developed programs centred on its use [6]. For example, Facebook is considered as an effective platform that allows educators to share class news and information with the parent of their children. Facebook allows for the creation of a private parents' group for the class and information may be shared only with particular parents in a unique way [25]. For example, when we do our research, we will contact families through the Facebook e-mail-messaging tool. Once families have agreed to be interviewed and provide their phone number, we will contact them to schedule a time for the interview. Facebook therefore may promote parental involvement in our centre's decision-making processes and provide an effective platform to increase families' participation rates.

In addition, even for those parents who are not able to attend information or cultural events due to lack of transportation, lack of child care, or incompatible work schedules [5, 28], and educators can use online access as an immediate way of sharing information. Email can be an effective communication tool for many families as they are able to respond to messages in their own time. The centre's website can also provide information to families and to share children's experiences. Overall, technology practices are an effective way to actually involve families.

\section{Challenges underpinning the use of technology with families}

The National Professional Standards for Teachers [29] encourages educators to use information technology in their daily work lives. However, as with any new technology, they bring both rewards and challenges.

- For educators:

Adopting a new work method takes time to learn and adapt. According to Rolfe and Armstrong [2], time, money and training were identified as key barriers and constraints that keep educators from adopting technology as useful tools. Studies also found that professionals are generally in denial about new technologies, as they believe that technology would take time away from getting work completed[21]. On the other hand, some early childhood educators complain that the increasing number of emails or messages from families negatively influence their daily lives as they normally reply during their non-teaching time. Electronic communication may be a common cause of misunderstandings [11]. The language used may be open to different interpretation and meaning by different people. In addition, the electronic equipment in the workplace is unable to run the updated software and it may take a long time to access the Internet in times of heavy demand.

- For families:

As a direct stakeholder of the meaningful partnership, most families are concerned about privacy and Internet security. In some family circumstances, custody issues and restrictive access may be problematic. Research shows some parents feel uncomfortable when information about their children is shared with other family members or caregivers on social media [9]. As leaders, we have to consider how to connect with parents safely and effectively. Moreover, another challenge is that in low-income families, they have less access to electronic and Internet technologies [30]. Studies pointed out the preferred method of contact by parents may be influenced by socio-economic status: low-income parents prefer to interacting face to face [23].

\section{Significance to Early Childhood}

There is a growing recognition of the importance of early years education and is reflected in Australian Government policies and programs aimed at supporting children's wellbeing by 
strengthening families and communities [3]. Developing and maintaining respectful relationship with families and their children, in embedded in the concepts of Belonging, Being and Becoming: The Early Years Learning Framework for Australia (EYLF) [31], the Family Schools Partnerships Framework [32], and the proposed National Professional Standards for Teachers [29]. It is imperative that we as early childhood leaders engage in critical reflection about our relationships and pedagogies with families. Therefore, we would provide families with multiple methods of communication and use technology to foster their involvement.

As leaders, we view educators' professional skills training as an essential aspect of enhancing their capacity to implement innovative and effective parent-staff strategies. Training to work with families will improve parent-educator communication and denotes early childhood practitioners' awareness of the importance of developing and extending their skills when working with families. Research reviewed by Waniganayake and his colleagues [16] emphasize that family participation in centre-based activities varies according to a number of factors and therefore, additional training input can provide guidance to bring differing perspectives together. Educators in our Centre need to acquire appropriate skills to learn how to engage families and communities. Plus, technology experts will be involved in training educators to learn how to use new electronic equipment or software.

Furthermore, the value of collaborative partnerships between educators, families and communities is also affirmed as one of the seven Quality Areas in the National Standard for Early Childhood Education and Care and School Aged Care [33], which emphasizes that 'respectful and supportive relationships with families are developed and maintained' (Standard 6.1). Likewise, the EYLF [31] also stresses that the importance of early childhood educators understanding diversity. This is described as educators who are 'culturally competent respect multiple cultural ways of knowing, seeing and living, celebrate the benefits of diversity and have an ability to understand and honor differences' [31, p. 16]. At the same time, Guilfoyle, Saggers, Sims and Hutchins [34] clearly state that for Aboriginal and Torres Strait Islander communities, 'family involvement is an essential component of culturally strong programming and support for families' (p. 68). Therefore, it is crucial to show our commitment to the inclusion of families in our Center, and as leaders we need to ensure all the educators are 'sensitive and responsive to diversity and difference [31, p. 13].

As leaders, we ensure that program information, forms, policies, and resources reflect the diversity of family types. We recognize that one communication method is not going to suit all families, and therefore as contemporary early childhood leaders, we aim to provide opportunities for conversation and reflection by offering the use of electronic media and online technology as it incorporate both written and oral forms of communication. In addition, in order to successfully engage families in service, all family members are encouraged to share their perspectives and views and to participate in consensual decision-making. For instance, the results of the surveys, the interviews and the questionnaires will be carefully discussed with families and educators. Families are encouraged to take an active role and establish appropriate protocols so that everyone involved in the Centre can make use of technology for professional work in ethical ways. Therefore, the partnership between educators and families is created from meaningful contact, connection and communication.

\section{Conclusion}

In summary, the aim of this research project was to investigate the use of technology intended to strengthen parental involvement in the early childhood education. It highlighted the importance of involving parents in their children's learning, as well as the critical development of meaningful partnerships between educators and families. It also examined the reasons of using technology instead of using traditional strategies by discussing the role technology plays in parental involvement. The research methods including the surveys, the interviews and the questionnaires were implemented before and during the action research. In this way, as leaders we would able to understand both families' and educators' views, the benefits of the approach, the difficulties which may be faced during implementation and suggestions on further improvement. Literature reviews were presented in three sections, and clearly demonstrates that using technology can increase the communication 
opportunities between educators and parents and also increases the opportunity to involve parents participating in center curriculum and program planning. Even for parents with multicultural backgrounds, the use of technology is valuable as it provides visual information for family members. The final part of the research project focused on the significance in relation to early childhood policy and practice.

Moreover, as leaders we have developed a better understanding in terms of appropriate and effective communication practices, with a focus on how the use of technology is critical in this process. At the same time, the implementation presents challenges such as adopting a new work method which takes time, misunderstandings when using email, educators' complains about the speed of running electronic equipment in the workplace, parents' concerns of privacy and Internet security and differing socio-economic factors. In order to positively respond to these challenges, as early childhood leaders we would reform our practice in terms of the Centre's vision and mission, professional learning and collaborative abilities.

\section{References}

[1] P. Duignan, H. Cannon, The power of many: building sustainable collective leadership in schools. Camberwell, Victoria: ACER press, 2011.

[2] S. Rolfe, K. Armstrong, Early childhood professionals as a source of social support: The role of parent-professional communication. Australian Journal of Early Childhood.35(3) (2010) 60-67.

[3] L. Arthur, B. Beech, E. Death, S. Dockett, F. Sarmer, Programming and planning in early childhood settings, $6^{\text {th }}$ ed., Cengage Learning Australia Pty Limite, 2015.

[4] A. Stonehouse, M. J. Gonzalez, Making links: A collaboration approach to planning and practice in early childhood services, 2nd Ed., Pademelon Press: Sydney, 2008.

[5] R. Chaboudy, P. Jameson, Connecting families and schools through technology. Book Report. 20(2) (2001) 52-27.

[6] C.Lewin, R. Luckin, Technology to support parental engagement in elementary education,Computers \& Education.54(3) (2010) 749-758.

[7] A. Harris, J. Goodall, Do parents know they matter? Engaging all parents in learning. Educational Research, 50(3) (2008) 277-289.

[8] S. M. Bouard, Tapping into technology: E role of the Internet in family- school communication. Cambridge, MA: Harvard Family Research Project, 2008.

[9] B. Somekh, D. Mavers, C. Lewin, Using ICT to enhance home-school links: An evaluation of current practice in England. Annersley, Notts, UK: DfES, 2001.

[10] K. J. Swick, R. D. Williams, An analysis of Bronfenbrenner's bio-ecological perspective for early childhood educators: Implications for working with families experiencing stress. Early Childhood Education Journal. 33(5) (2006) 371-378.

[11] O. Christine, Using technology to increase parent involvement in schools. TechTrends: Linking Research and Practice to Improve Learning. 57(6) (2013) 28-37.

[12] H. Chen, C. Yu, C. Chang, E-homebook system: A web-based interactive education interface. Computer \& Education. 49(2) (2007) 160-175.

[13] L.Thornton, P. Brunton, The parent partnership toolkit for early years, London: Optimus Education, 2010.

[14] A. Fink, How to conduct surveys: a step-by-step guide, $3^{\text {rd }}$ ed., Thousand Oaks, CA: SAGE Publications, 2006. 
[15] J. Rodd, Leadership in early childhood the pathway to professionalism, $4^{\text {th }}$ ed., Australia and New Zealand: Allen \& Unwin, 2013.

[16] M. Waniganayake, S. Cheeseman, M. Fenech, F. Hadley, W. Shepherd, Leadership contexts and complexities in early childhood education. Australia: Oxford University Press, 2012.

[17] G. Hornby, R. Lafaele, Barriers to parental involvement in education: an explanatory model. Educational Review. 63(1) (2011) 37-52.

[18] C. McWayne, M. Broomfield, J. Sidoti, N. Camacho, Facilitators of and challenges to interagency collaboration: An early childhood perspective. NHSA Dialog: A Research-to-Practice Journal for the Early Intervention Field. 11(2) (2008) 90-109.

[19] Australian Bureau of Statistics, Census of Population and Housing. http://www.abs.gov.au/ausstats/abs@.nsf/Latestproducts/3416.0Main+Features2Mar+2013

[20] T. N. Hohlfeld, A. D. Ritzhaupt, A. E. Barron, Connecting school, community, and family with ICT: Four-year trends related to school level and SES of public schools in Florida. Computers \& Education. 55(1) (2010) 391-405.

[21] L. H.Ho, C. Hung, H. C. Chen, Using theoretical models to examine the acceptance behaviour of mobile phone messaging to enhance parent-teacher interactions. Computers \& Education. 61(2013)105-114.

[22] R. Bridgemohan, V. W. Noleen, V. S. Christie, Home-school communication in the early childhood development phase. Education. 126(1) (2005) 60-77.

[23] S.G.Kosaretskii, D.V. Chernyshova,. Electronci communication between the school and the home. Russian Education and Society. 55(10) (2013) 81-89.

[24] M. Larocque, I. Kleiman, S. M. Darling, Parental involvement: the missing link in school achievement. Preventing School Failure. 55(3) (2011) 115-122.

[25] N. Park, K. F. Kee, S. Valenzuela, Being immersed in social networking environments: Facebook groups, uses and gratifications, and social outcomes. Cyber Psychology \& Behavior. 12(6) (2009) 729-733.

[26] A. C. Wilson, The effects of web-based communication and contact on parental involvement, Action Research Exchange. 4(2) (2005) 1-10.

[27] R. Mullen, L. Wedwick, Avoiding the digital abyss: getting started in the classroom with YouTube, digital stories, and blogs. Clearing House. 82(2) (2008) 66-69.

[28] I. Blau, M. Hameiri, Teachers-families online interactions and gender differences in parental involvement through school data system: do mothers want to know more than fathers about their children? Computers and Education. 59(2) (2012) 701-709.

[29] Australian Institute for Teaching and School Leadership. National Professional Standards for Teachers. Retrieved from http://www.aitsl.edu.au/australian-professional-standards-for-teachers.

[30] S. R. Sirin, Socioeconomic status and academic achievement: a meta-analytic review of research. Review of Educational Research. 75(3) (2005) 417-453.

[31] Department of Education, Employment and Workplace Relations. Belong, being \& becoming: The early years learning framework for Australia. Canberra, DEEWR, 2009a.

[32] Department of Education, Employment and Workplace Relations. Family-school partnerships framework: A guide for schools and families. Canberra, DEEWR, 2009b. 
[33] Australian Children's Education \& Care Quality Authority. The National Quality Standard for Early Childhood Education and Care and School Age Care (ACECQA). http://www.acecqa.gov.au/national-quality-framework/the-national-quality-standard.

[34] A. Guilfoyle, S. Saffers, M. Sims, T. Hutchins, Culturally strong child care programs for Indigenous children, families and communities. Australian Journal of Early Childhood. 35(3) (2010) 68-76. 